\title{
Model Village: Political and Economic Symbols after A Landslide Disaster in Southwest China
}

\author{
Yongxiang Li \\ Yunnan Academy of Social Sciences
}

The study of model villages has received extensive attention in academic circles of Chinese studies. However, studies on post-disaster recovery and reconstruction of model villages are rare. This paper discusses the political and economic significance of the construction of model villages after landslide disaster, and the difference between model villages and non-model villages. At the same time, the paper discusses the relationship between model village and community demand; and various problems and contradictions in the construction of a model village. With the advancement of the policy of precise poverty alleviation and rural strategy in China, the research on model villages will receive much attention. The construction of post-disaster recovery model village can provide an idea for post-disaster reconstruction in future.

\section{Model Village, Disaster Reconstruction and Community Demand}

A model village presents a model of successful experience for other villages. It does have the advanced (xianjin) and model (mofan) elements, rewarding them symbolically and materially, and holding them up for study and emulation (Diamond, 1983). Other villages should do things according to the model set by the model village. "In Agriculture emulate Dazhai, in industry emulate Daqing (nongye xue dazhai, gongye xue daqing)" is an important historical example of the use of the idea of "model." Today's model village is different from that time. The purpose of Dazhai and Daqing was a spirit of working hard collectively to achieve collective output/goals. Everyone in the country should work hard like them. The model village today mainly shows successful economic development, which is different from Dazhai and Daqing of a spirit of working hard collectively.

The construction of model villages has been paid more and more attention in the contemporary economic development. It becomes an important way of promoting local development since it directly targets to project grant application. As a result, various model villages have been derived, such as model villages of economic development, national unity, ecological demonstration villages, tourism development demonstration villages, poverty reduction demonstration villages, and so on. The model village construction has become an integral part of the rural revitalization plan, which has aroused the wide interest of scholars. Ethnic solidarity model village is one of the most recognized model villages. Certain scholars have studied the model village project in depth (Wang, 2018), the model village development methodology (Zhang, 2018), and some have focused on the role of model villages in poverty reduction (Jia, 2017). There are also discussions on ecological construction model village in the role of environmental protection and new countryside construction (Huo et al., 2017). On the whole, model villages are considered to have superior effects in terms of township civilization, neat appearance of 
villages and democratic management compared with non-model villages (Hu et al., 2011). Scholars believe that models, pilots and experiments are considered to be significant features of China's policy process (Ahlers and Schubert, 2013). However, there are also some people who criticize the unfair project competition, power and resource allocation and wide social network problems existing in the construction of model villages $(\mathrm{Li}, 2018)$. The acquisition of model village project is closely related to the social network and social capital of local cadres. These research results show that model village construction does have certain advantages and disadvantages in rural development in contemporary China.

However, it is an indisputable fact that with the implementation of China's rural revitalization plan, model villages will attract attention from all sectors of the society and scholars. Model villages and disaster recovery and reconstruction will be combined, although not as many as the ethnic unity model villages, but they have emerged as post-disaster recovery and reconstruction model villages. The model village of disaster recovery is of great significance, because the model village is built on the basis of community. In disaster research, many scholars emphasize the importance of community demand-orientation. Anthropologist Torry (1979) points out that the theory of disaster research is the theory of community, namely, the continuity and change of community. Community demands are important because disasters are deeply embedded in the political economy and social culture of a society (Oliver-Smith, 1999; 2005). Once community demands are ignored, local villagers will lose confidence in community recovery and reconstruction.

The model village then not only has good construction and infrastructure, but also has deep symbols of social and political meaning. The model village is usually constructed near the main road, not far from the town and in an open field of vision. These conditions are mainly designed for the convenience of high level leaders to visit and "investigate" (diaocha). Two following facts are important when building a model village. First, many high-level leaders do not want to go to difficult places or places far from main roads. They prefer to visit a place near town or on a road to check lower- levels' work. The model village shows them low-level cadres' successful work. Secondly, the evaluation of low-level cadres' jobs is decided by high-level leaders, who also control the promotion of low-level cadres. Low-level leaders must clearly understand these two principles so that they can get good evaluations from high-level leaders. Susan Whiting's (2001) work shows that the cadres' evaluation system is a powerful tool of bureaucratic control, and depends on political organizational and leadership abilities as well as actual achievement. Good evaluation is linked with material and nonmaterial both rewards, as well as transfers and promotions. Definitely, the cadres' actual achievement is linked to their economic records. These factors are the reasons why people select places near roads or towns for reforestation projects (tuigeng huanlin) and model villages. In academic circles, there is a very beautiful name for this kind of project, called Road Side Project (lubian gongcheng).

The scope of model villages is expanding today, including model households, model townships, model counties, model regions, etc. Yunnan province is China's model region in ethnic unity and progress. There is no doubt that the construction of model villages is valued in China's rural construction and development. With the promotion of China's rural revitalization strategy, it is of great significance to summarize the experience and study on model villages.

\section{Landslide Disaster in Shuitang Township of Xinping County of Yunnan in 2002}

On August 14th of 2002, serious landslides happened in the Ailao Mountains in Shuitang and Gasa Towships, Xinping Yi-Dai Autonomous County, Yunnan Provence, causing a lot of damage. Bajiaoshu village of Jinchang Cunweihui (Village Administration Committee) was washed away, and 14 people died in the village. About half of Mannuo village of Xinzhai Cunweihui was washed away, and 17 people died. Dashiban, Dashuijing and Songshujiao of Nanda Cunweihui were washed away, and 13 people died. The landslide in the town of Shuitang led to 4 deaths. The landslide in Pingtian of Gasa killed 9 people. According to the local government, the landslides led to 63 deaths, 801 houses' collapse, and 2000 people becoming homeless. The landslides also washed away 221 cattle, 1463 pigs and 2704 ducks and chickens. 
The damage to roads, utilities, bridges, agricultural land, and other infrastructure was severe. The county government said that they lost more than 300 million yuan (37 million US dollars). Since all landslides happened on August 14, it was named "8.14 landslides disaster". The county government claimed that this had not happened within 100 years. For a long time, people have been struggling with the memory of the landslides. A Dai man told the story of the landslide:

That was a night that our village was in disorder. We tried as much as possible to move our properties to the mountain behind the village. My wife and I were busy moving the TV and other expensive things out. Our village's location is special. There are two rivers around our village, at left and right. The left one is dangerous since floods always come from that side. The right one is small, has rarely floods, and has a lot of trees. We believe right side is safer. There is a mountain behind the village. All villagers tried to move their properties to the mountain close to the right side. Since it rained terribly and was dark, people could not find family members, and could not recognize people when they saw them, but they kept moving things. I sometimes fell down, sometimes broke things, but the worst thing was that I could not find my wife and kids. The water in the left river was becoming bigger and bigger, and I realized that I needed to find my wife and kids. Then, when I started to go to the right side of the river; suddenly, I heard a tremendous sound, I saw a huge 20 meter- high thing came out from the left side of river and disappear. Within 3 seconds, half of our village was gone. All the people in the village were scared like lost souls. Nobody could say a word for four hours. The process of the landslide itself only took about 5 seconds, but I cannot forget the fear for my life. I lost my wife, and we even cannot find out her body. She was washed away somewhere by the landslide, but we do not know where. 17 people died in our village.

Shuitang Township is the place where the most serious landslides happened in the county, and the township is still in a dangerous situation for a long time after the disaster. In the post-disaster recovery and reconstruction, relocation has become one of the most important tasks. 2225 families and 8551 people must move out of their original villages. These people involve 65 village teams (50 natural villages) of 10 Cunweihui (administrative village). This is the biggest removal in Shuitang and also in Xinping history.

\section{Model Village: New Shanghai Village}

The recovery construction started soon after landslide disaster. More than 2225 families needed to relocate. In Shuitang's relocation township, there are two kinds of village construction; one is ordinary villages, and the other is model villages. Here model village does not necessarily mean that they could do the best way of constructing a new village, but it means that the township government received 2 million yuan from Shanghai people's government, and needs to build a model village to show the great contribution from Shanghai People's Government. Then, a Han village called Pingzhangtian was selected as a model village. The reason that the local government selected Pingzhangtian as a model village is that the village's economic situation is much better than that from other villages. The local government believes that Pingzhangtian can do a much better job since they are richer than people of other villages. They, of course, soon become the example of the best village construction in the county during the reconstruction period. Then, the name of Pingzhangtian is changed to "New Shanghai Village".

\section{The Early Plan of the Location}

The site selected for the model village was on the top of a small hill where Dai people had planted a lot of sugar cane. There are no trees on the site, since people plant sugar cane, but there are many bushes half way down the hill. To the east is the mountain called Changchong Shan meaning long worm mountain; to the south is Shuitang town; to the west are the Ailao Mountains through which passes the main road from Shuitang to Zhelong Township of Xinping; and on the north is a broad view of fields area 
and also of the Han village named Balatian, which was moved from the mountains during the 60s. The land on the hill belonged to Dai people in Xiaomaka originally.

After the landslides, the local government invited two geologists to Shuitang to find a safe place for people to live. When the geologists came here, the place was definitely selected for at least one hundred families to live. Of course, at the beginning of that time, nobody knew who would move there, or what kind of village would be constructed. Even when Pingzhangtian village was selected from among the landslide-affected villages to move to the selected spot, the government still had no plan to build a model village. They only wanted to build an ordinary village.

When I came to the place with the chief leader of the Shuitang government in the winter of 2002, the view I could see was only sugar cane. The sunlight of winter was not hot but warm. I saw the smoke in Balatian village only $1 \mathrm{~km}$ from the hill. Occasionally, I could hear cocks crowing. The road from Shuitang to Zhelong crosses the village of Balatian, but the noise could not reach this silent hill. Changchong Mountain is a symbol of luck and secret in local Dai thinking. This is why so many Dai people opposed planting sugar cane on the mountain. Through a very simple road on the hill, I saw a simple and crude house on the edge of sugar cane land. Dai people rent this land to a person to plant sugar cane. The person was told by the local government to cut the sugar cane down and sell to the sugar mill as soon as possible. The government wanted to send a team to survey the land and design houses. After local leaders discussed the problem, the local government decided to ask farmers to finish house construction before the rainy season which would begin in early May of 2003.

After two weeks, when I came back to the hill, I saw no sugar cane left. The designing team was working hard to survey the land. The obvious change was that the bulldozers were roaring to flatten the soil. The land became red under the sunlight. After the bulldozer had finished their jobs, the design team started to survey specifically the land for the design of each house. All houses were the same in initial design. Each house (family) got 120 square meters. Before the villagers came to draw lots, the government had the responsibility to finish what were called "three supplies and one flatten" (santong yiping) which means electricity, water, road (tongdian, tongshui, tonglu) and flattening the soil (tuiping tudi). The government needed to finish all things early and design the houses and make clear demarcations for villagers. This would avoid arguments among the villagers, so that villagers could concentrate on construction. The "three supplies and one flatten" is the government responsibility for all villages in Shuitang who needed to move, not only for this village.

The third time I came to this hill, I saw the land had become terrace land, and the bulldozers had not stopped and were doing their final work. The designing team finished the basic work of design. According to their suggestions, 145 families could be arranged to live there. Some farmers had to build retaining walls (dangqiang) behind their houses if they were located in a high terrace area. Those who got the flat areas did not need to build a wall. The government did not build the walls but asked the farmers to do it.

The lot drawing day was exciting for all villagers. All people were asked to gather together at the site. To people's surprise, the leader of the Shuitang government suddenly announced that the village had received 2 million yuan from the Shanghai people's government. Each family would get about 10,000 yuan for house construction. The village would be named New Shanghai Village (Shanghai xincun) and be a model village. For the purpose of building a new, beautiful and successful village, the structure of the village and houses would be redesigned, and the drawing of lots would be delayed. The leader asked the villagers to wait for the result of the new design of the village.

\section{Direction, Stratum and Overall Construction of the New Village}

After the announcement, villagers and government officers were all excited. The new design would require enlarging most houses from 120 square meters to 154 square meters. The bulldozers showed their power again in this area. According to new plan, the village would be arranged as a model village for specialized pig-raising. The government would give preferential treatment to support them. Farmers felt very lucky with this information. They started to use the name of Shanghai. Many of them even believed 
there were two Shanghai in China; one was the real Shanghai in eastern China, and the second was definitely in Shuitang. They preferred to use the word Shanghai instead of New Shanghai Village. I heard everybody in rural areas including government cadres and farmers saying, "I will go to Shanghai", "I just come back from Shanghai", or on mobile phone, they said: "I am in Shanghai now". All people know that Shanghai meant the new model village in Shuitang.

The directions of New Shanghai Village are very important. This is a hill, and there are four directions. One direction faces Shuitang town, one faces the main road, the third faces a huge area of land, and the fourth direction faces Changchong Mountain. The former three directions are important since people can see the village from a far place or even from a car or bus. The last direction, the fourth one facing Changchong Mountain is not important because there are no people living in the mountain. According to the government plan, the fourth direction would be provided for poor people who had no money or ability to build beautiful houses, and they would get 120 square meters for their houses, which is less than those provided to people facing other directions. They can choose to build tile-roofed houses (wafang) or asbestos-roofed houses (shimian wafang). The other three directions will be arranged for richer people and required building houses with flat concrete roofs (shuini pingdingfang). They got 154 square meters for each family. Poor people must draw lots for properties facing the mountain if they had no money to build good houses. The result of drawing lots was coordinated with the plan designed by local government.

The construction immediately started after drawing lots. The movement of many tractors, trucks and other vehicles started there. Sometimes tractors and trucks tried to carry more material to earn more money, but the road was very narrow, which nobody could pass. This situation occurred frequently since so many vehicles came including government cars for checking the process of construction. With more and more people coming, restaurants and Karaoke rooms were built, which was very lively. For the successful village construction, the government established construction headquarters in the village and the county government sent a team to help build the pigsties. This was the kind of headquarters that only a model village was given, not other relocation villages. All these arrangements showed that local government tried their best to build the model village. All high-level cadres, leaders and other visitors were taken here without exception for observation and investigation on relocation. The model village showed its importance.

However, villagers and local government had different opinions and understandings about spending the 2 million yuan. The local government said part of the budget of 2 million yuan should be used for buying land from Dai people, building roads and a modern water system, and connecting electricity. They also needed money to rent bulldozers to flatten out the terrain. All things cost money. The farmers, however, did not agree with this. They thought the above things were local government's responsibility whether Shanghai had been given 2 million yuan or not. The money from the Shanghai People's Government should be used to support villagers, not for the road, land, water, electricity and renting bulldozers since that money should already be counted in the government budget.

According to the farmers, each family should get:

1. 2000 yuan for relocation fee

2. 900 yuan for building a marsh gas heating and cooking system

3. 10,000 yuan for each family from the funds contributed by the Shanghai People's Government

Farmers believed that No. 1 above was the money all people who had to be relocated would receive. No. 2 was special money for building a marsh gas heating and cooking system for New Shanghai Village only, and third one was the money from Shanghai People's Government for special help to the people there. Therefore, the total money that each family should receive was 12,900 yuan. However, farmers said that the local government did not give them 12,900 yuan. Instead, they received the following things from the government:

- 2000 yuan for relocation fee (banqianfei), which is not from the Shanghai people's government 
- 7 tons of cement, which were worth 1400 yaun

- 3 pigsty doors, which were worth 100 yuan

- 2 toilet doors, which were worth 70 yuan

- 600 big hole bricks (kongxinzhuan), which were worth 690 yuan

- water pipes, worth 200 yuan

- sand, which was worth 369 yuan (but some farmers said should not more then 150 yuan)

- gravel, which was worth 130 yuan.

The total money they received was 4950 yuan, which was far less from 12,900 yuan. If one deducted the 2000 yuan for the relocation fee, each family received 2950 yuan out of the 10,000 yuan they believed they should get from the contribution made by the Shanghai People's Government. This was far from their hope of receiving support of the model project. The final decision, of course, was absolutely controlled by the government, and no discussion or negotiation occurred between farmers and local government.

The construction speed and quality differed greatly among the villagers. Some people finished the second floor before others had even started. Some villagers started construction, but after finishing half way, they did not have money to continue the construction. Then they had to stop to working and try to find some money to continue. Some people were struggling with the wall (dangqiang) behind the house since they built it very poorly the first time, and when the rainy season came, it slid down and they needed to rebuild it. For those who drew lots on very steep areas, they needed to spend a lot of money on the wall behind the house. For many reasons, the villagers could not unify the process although the government requested them to do so.

The only thing they could unify was the so-called sanpeitao or three sets, meaning pigsty, toilet and marsh gas burner. These had unified designs and needed to be finished in a certain time since some technical people would go back in a short time, and all villagers should finish their sanpeitao together within the deadline given by the government. This was easy to finish within the time given by the government since all materials for Sanpeitao were free and paid out of the 2 million yuan from Shanghai. The Sanpeitao was something farmers really got from the project fund from Shanghai.

The different opinions and actions in New Shanghai Village reflect conflicts of interest between the farmers and local government. The local government had to pay for construction of infrastructure, such as water supply, roads, electricity and flattening the terrain, whether or not they got support from Shanghai, but after they got the support, they could also save their money for other places. This is not difficult to understand if many people needed help in the area. Actually, they did not need to discuss or negotiate with farmers as they had the power of making a decision. The villagers could only listen to government explanations. They also had no place to state their opinions.

However, New Shanghai Village is the best one in Shuitang and also probably in the county. There is a road in front of each family's house, and in the central part of the village, and there is a public square of 2500 square meters composed of basketball court, tuoluo court, and green area. There is a meeting room near the basketball court. The basketball court was designed according to the national standards; and the green area had many trees including some evergreen trees (wannian qingshu) planted by the main leaders of the county government as a symbol of the support of the county government to the people who suffered from the landslide.

\section{Relocation of Poor Families in the Village}

With the government requirements and very limited time, many people had no spare money for construction under the very hot weather near the Honghe River. Many villagers came early and went back late, and put all their time and energy into the construction. I met a young man who was one of the poorest people in the village, but he was the first person to finish his house and move into the new house in July, 2003. Many villagers felt admiration for him, although his house was simple and its direction was facing Changchong Mountain, the poor people's direction. The Yuxi daily, a party newspaper in the 
prefecture, published an article telling his story of quickly building his new house in the new village. There are only two people in the family, he and his mother who is 68 years old. He told me the story why he was poor:

My father died this year. He was sick and we sent him to the hospital. We did not know anything about the sickness. His stomach became bigger and bigger. The doctors also did not tell us. We spent several thousand yuan in the hospital, but it did not cure his sickness. He finally died. We do not have money to build a house since the money has been spent to try to cure father's sickness. I can only build an asbestos-roofed house (shimianwafang). I borrowed more than 8000 yuan for the house, and this did not include materials I borrowed from friends.

At the end of 2003, many villagers started to move into new houses before Chinese New Year. The local government especially cut out of iron, painted six big yellow characters saying "nanda shanghai xincun" on the roof of the meeting room. They also wrote an inscription on a stone tablet in the meeting room:

Great benefits under the heaven come from water, but disaster also comes from water. At 4 am on $14^{\text {th }}$ of August $2002\left(6^{\text {th }}\right.$ day of $7^{\text {th }}$ month of the Chinese calendar), the areas of Shuitang, Zhelong and Gasa suddenly received a lot of rain. Landslides happened in this area. Land moved with water, and stone moved with land. The landslide occurred in the Nanda area. 350 houses were damaged, 8 people died, 7 people have never been found, 1 person had a major injury, 8 people had slight injuries, and roads and other utilities were blocked, the direct economic loss was 33,186,000 yuan.

After the landslides, the marks of landslides were everywhere. Danger also existed in all the villages. Farmers could not go home. The disaster affected the leaders' hearts, and startled the central government. The government of every level immediately organized cadres, soldiers, and people to rescue victims from the disaster, employing the spirit of "one side has a problem, eight sides come to help" to console victims and rebuild homes. We received 2 million yuan support from the people of Shanghai and quarter of million yuan from the government of different levels and many goods and materials from people inside and outside the county.

Today, the new village has been constructed. All people are glad and happy. For the memory of the support of people of Shanghai, we, 146 families in the village have decided to change the name of village to "New Shanghai Village". We also wrote this inscription on a stone tablet in order to educate our future generations not to forget the help from the central, provincial, prefecture, county and township government, and all those who have helped us.

All villagers of New Shanghai Village December, 2003.

New Shanghai Village had not encountered situation that people did not want to move to the village if their houses had been finished. According to the leader of Nanda Cunweihui, those whose houses were unfinished were doing wage labor jobs. They needed to get some money to build their houses. About 100 families had moved into the village, and people were happy to live there, the leader said.

\section{Unfinished Houses, Poverty Families and Subsidies}

The construction speed of New Shanghai Village was slower than planned and imagined by the local government. The rainy season finally arrived, and the farmers still could not move into their new houses. The government asked the farmers to speed up the construction of houses, but they could not continue since rainy days were difficult for construction. At the same time, the rainy season was also the busy season for agriculture. Farmers had to concentrate on agricultural fieldwork for sugar cane and walnuts. 
Then, the autumn was even busier with the harvest of rice, corn, and walnuts. Pingzhangtian has the best reputation for walnuts in the county, and villagers are waiting to sell walnuts to get more money for the construction. As winter approached, farmers began to concentrate on construction. During winter time, the high-level government came and checked the process of the construction. The local government found that not so many people had finished their construction. The actual situation was that 75 families had finished, 15 families had moved, but local government reported 111 families had finished, and 45 families had moved into new homes.

At the end of 2003 and beginning of 2004, prices in China went up dramatically. The price of reinforcing bar increased from 2200 yuan per ton to 4200 yuan per ton. Cement increased from 200 yuan per ton to 260 yuan per ton. The price of transportation also increased since the price of gasoline went up. These things made the construction even more difficult since the people who had not finished were mainly poor people. They originally had no money to build their houses, and with the addition of rising prices, they really were not able to finish the construction. The government, of course, did not want this to happen, especially in the model village. After the local government wrote a special report to the provincial government asking them for helping the poor people in this model village, the Department of Civil Affairs (minzhengting) of the Yunnan provincial government agreed to add a quarter million yuan for additional help to the village. This was special help to poor people in the village who were affected by the price spiral. The provincial government thought this would be enough to solve all problems.

However, there was argument among villagers over how to allocate the quarter million yuan given by the provincial government. Many people did not agree to give money to those who did not finish their houses. They believed that their own incomes were not so different. The fact that they finished the construction did not necessarily mean they were rich. They just obeyed the government's advice and borrowed money from friends and banks to finish the construction. Those did not finish the construction not because they were poor, but because they did not want to obey the government orders, and did not want to borrow money. If this method would get additional help from the government, everybody would stay and wait for help. People who finished the construction wanted to allocate the money equally. The local government found this argument was not good for solving problems, and then decided to not give money to anyone. One local government officer told me that there were now only170,000 yuan left from the original 2 million, plus additional money from the provincial government, that was about 430,000 yuan left for the construction of New Shanghai Village, which was a lot of money compared with other villages.

\section{New Shanghai Village: A Model for Raising Pigs and Sickness of Pigs}

The model village was designed by the government as a specialized village for raising pigsty. This is why every family got a free pigsty. After they finished the construction, they needed to raise as many pigs as possible to show outsiders their success in raising pigs. The government would then take visitors to see. Many people started to buy pigs and raise them. I saw one family who had 12 pigs, which meant they really started the program. However, after the Spring Festival 2004, the pigs got a serious sickness, which seriously changed the model of raising pigs. Many families said all their pigs had died. The symptom of sickness was swelling including pig's head, mouth, eyes, foot and hoofs; some pigs also had diarrhoea and asthma, and had a running nose. The sick pigs could not walk. The agricultural extension experts came several times but they did not know what kind of sickness it was. Finally, the local animal hospital station (shouyizhan) began to do anatomical studies on pigs. They found out that the pigs' lungs were swollen, but they really did not know what kind of sickness it was, or why this happened. Obviously, their very limited education and knowledge with poor equipment were not able to explain this complicated sickness. It required a high-level of scientific work which they did not have. The situation was even worse for those poor farmers who did not have any education or knowledge about the sickness and medicine. However, they went to market to buy many medicines to do injection. They were trying as many medicines as possible to hopefully cure the illness of their pigs. This did not work since they did not know 
what the sickness was or what kind of medicine they were buying. They just did the injection and if it did not work, they changed the medicine. Sometimes extension people also came and gave injections, but like farmers, they also did not cure any pigs.

Many pigs died, and more and more pigs got the disease. Local government and villagers finally realized this was a very serious and dangerous contagious illness. The government started to worry about the illness that could spread to other places, and realized they needed to do prevention. They then immediately laid down a regulation that ill pigs were not allowed to be sold in the market. However, in order to reduce their losses from the illness, some farmers ignored the regulation and stealthily sold the pigs in the market. Then, the next day, the pigs died in other places. After the situation of stealthily selling pigs in the market was spotted, the government sent a team to the main road near the model village to stop the sale of ill pigs in the market. Villagers began to stop this action and brought ill pigs to wild areas in the mountains and let pigs die there. Some families began to kill pigs before they died, and ate the meat. The government did not stop either of these two kinds of behaviors. Many farmers spent much money, but no pigs were cured. This situation happened after a chicken sickness, which also caused lose money.

The illness of pigs raised doubts among farmers and others about the model pig-raising village. Almost all villagers lost their pigs and people started not to raise many pigs. Those who wanted to make money by raising pigs in the village received a big blow. Some people even did not raise any pigs after that illness. One family dismantled the pigsty built by the government for free and built a new kitchen, which strongly challenged the government plan of raising pigs. These people said the farmers needed a toast room (kaofang) to dry walnut, not a pigsty. They thought that the government design was not in accordance with actual situation in this area. Some families raised their pigs in the old village Pingzhangtian and they thought New Shanghai Village was too hard for raising many pigs.

\section{Non-Model Village: Xiaomaka}

Many villages relocated during the reconstruction were not model villages, and here, I chose one village named Xiaomaka to do comparative study with the model village. People in Xiaomaka were not as lucky as people in New Shanghai Village, who got support from Shanghai and from the Yunnan provincial government. People relocated to Xiaomaka were mainly Yi people from Hetaoping, which was also severely damaged by the landslides. There were many reasons that the local government did not chose Xiaomaka as a model village, such as being too small or having just a small number of households that needed relocation, which made Xiaomaka not representative.

Xiaomaka is only $1.5 \mathrm{~km}$ from New Shanghai Village, but the government treated it very differently from the model village. Xiaomaka and New Shanghai Village were different before the relocation, since there were no people living at the site of the model village, but there were already 15 Dai families in Xiaomaka. Xiaomaka is a place where outsiders moved to mix with original villagers there. However, the Dai people in Xiaomaka are also people relocated from another place. The land around Xiaomaka belongs to people in Damaka. In 1980s, a Dai village moved to the site of Xiaomaka and exchanged land with Damaka. When the government discussed the relocation and land expropriation after the landslides, they only discussed the issue with people in Damaka, not with people in Xiaomaka.

When I first came to this place with leaders of the Shuitang government, I saw that it was a very steep place with some terraces planted with sugar cane. According to geologists, it was a safe place for about 50 families. The geologists' words were the main reason for the government to choose the place for relocation. When I first saw people working on the construction in the village, they asked: what are you marketing to us? What do you want to collect or purchase? You came too late; our houses have been contracted to other people. When I told them what I was doing, they asked: why don't you take a car to come here? In their idea, people from Shuitang always come by cars, not by bus.

Xiaomaka is very different from the model village. The government only gave 2000 yuan to each family for relocation plus "three supplies and one flatten" (santongyiping) which means water supply, electricity, road and flattening the ground. Some people also thought that these things were not as good as 
those the government provided in the model village. There were no marsh gas cooker, toilet or pigsty here, what were called "three sets" (sanpeitao) in the model village. Villagers had to pay for all those things themselves, and people here could not afford them. Most of the villagers had no toilets, and there were no public toilets in the village. The pigsties were very simple. I visited one family who had finished their house, and I saw the house was very simple, without a pigsty or toilet, but the host said they had spent more than 8000 yuan for the house. This kind of situation I did not find in the model village. Clearly, this was not a place the government was interested in although it was very close to the road. One villager said to me:

Dakou cunweihui is one of the poorest cunweihui in Shuitang, and Hetaoping is the poorest village in Dakou. We are the poorest, but we did not get help. They (the Han in the model village) are rich, but they got the most. This does not accord with the government policy, but we have no place to express our opinions. Even if we did go to say something, they would ignore us.

One old man also said to me when we discussed the Xiaomaka and Hetaoping villages:

There are no people poor like us in Hetaoping village. We originally had less land but now we have more people, so we needed to go to many places to reclaim wasteland. Historically we are poor. Before liberation, the richest family only had two horses. There were no really rich people in the village. During the class demarcation time, we only had two middle peasants (zhongnong). We even had no upper-middle peasants (shangzhongnong), and needless to say rich farmers called funong or landlords called dizhu. After liberation, when we saw people from outside, we still ran away. We also had no accountant in the village since we had no one with any education.

According to what the people in Xiaomaka told me, they had no public toilets, not enough water pipe, no marsh gas system. Their road was not as good as that in the model and other villages. The most difficult thing was no nearby agricultural fields, and their farming fields were very far from the village. The furthest place was about $20 \mathrm{~km}$ away. It was not possible for them to have time and energy to do any agricultural work after walking there. In many places, they could only do a few hours' work and then needed to come back home.

48 families were designated to move to Xiaomaka village, mainly from Dakou Cuiweihui. Among them, 30 families were Yi, 15 families were Han from Dakou and 2 families were from Sichuan Province and Zhenyuan County of Simao Prefecture. Visiting Xiaomaka, I had a different feeling from visiting the model village. Although 48 families were assigned this place, more than half of them had not finished their house construction. Many of them only finished half of the construction and then stopped and left. With poor quality construction, money was wasted, and they needed to rebuild. Many home sites contained nothing but grass. Although some families had finished their houses, they had not moved in. Some people moved into the new houses for a while, but then moved back to the old village since Xiaomaka was not convenient for agriculture. By August 2004, two years after the landslides, only 9 families had actually moved into the village. People only planted some bananas or vegetables on the house sites to lay claim to their property rights.

The differences between Xiaomaka and New Shanghai Village show the distinction between a model village and a non-model village. This is not an occasional example, but it shows that the intervention of state power can make things very different. After New Shanghai Village was built, one of my friends in the local government said to me: "If you can find some money from America, we can build a New American Village." We laughed and said that we could build an international model village, and probably, we could put it in Xiaomaka.

\section{The Political and Economic Symbolism of the Model Village}

Nobody knows how many cadres, leaders and news reporters have visited the model village. Sometimes cadres and leaders from different places and levels came to the village many times each day. 
Some leaders and cadres only came here to visit; some of them came for investigation (kaocha); some leaders came to check on the job that the low-level government was doing for relocation after the landslides. Some of them only accompanied high-leaders to do investigation, and some of them had no purpose but just to look at the model village. All visitors from outside were taken to the model village to look at what the local government had done for relocation after landslide. This is a clear demonstration of the symbolic significance and the political and economic meaning of the model village. Its neighbor, Xiaomaka, a village only $1.5 \mathrm{~km}$ from the model village, almost had no visit by leaders and cadres at all. High leaders wanted to see good news, not difficult situations. Some villagers said: "We do not have opportunity to reflect on problems. They (leaders) just come here by car, stay for a few minutes, and then go to a restaurant."

The New Shanghai Village is a model village that local government wants to use to test a way of relocation or migration from one place to another. Many factors have been taken into consideration when the local government designed the relocation after the disaster, such as farmers' income-raising pigs, villagers need a convenient place to leave-good houses and proximity to the road and town. Villages specializing in raising pigs, chickens, sheep or cows, or planting fruits or medicines are called specialized villages (zhuanyecun). Small town construction (xiaochengzhen jianshe) and specialized village are valued by the Chinese government for rural development in the future. The model village is an example of them, but the key thing here is that they got 2 million yuan from Shanghai People's Government so that they could accomplish it.

However, they also had some difficulties. First, it was not easy for all villages to build houses like the model village. In Shuitang, 2225 families needed to move after landslide, but only 146 families got support from the project, which accounted for about $6.6 \%$ of them. In other words, $93.4 \%$ of the villagers did not get help as those in the model village. The model village was too special since they got 2.25 million yuan from outsiders. Many poor people or people who needed help could not get money since the money was concentrated in one village. This situation shows that the government allocation to the villagers was not fair even though people in the model village still did not get as much money as they expected.

Second, the number of specialized villages was very limited, and it was difficult to do cooperation among villagers. Once the government approved a village to be a specialized village, people there would benefit from the policy, but farmers would also pay for this. Whether the residents like it or not, the production patterns would be changed according to the specialized village plans approved by government. If the government approved a village for pig-raising, all villagers needed to raise as many pigs as possible since they benefited from the policy. The problem was that some farmers did not do it since they did not like raising many pigs. The model village was a good example of this. By contrast, one family in Xiaomaka raised 22 pigs, but did not benefit from the model village policy. Third, there was no good and effective way to evaluate model villages, so it was difficult to prove that the investment or plan for a special model village had achieved its goals. We need a specific way to evaluate the results of a model village or government plans, and to make sure something that we have done or something that we need to do or research more. If there are no criteria for evaluation, the political significance is bigger than the realistic or economic significance. This means that the New Shanghai Village is a model village, but it is not a village that performs the best, rather it is a village that received 2 million yuan from the Shanghai government, so it became a model village. It is a model village that the local government made with the support from Shanghai. If they had not received money from shanghai, there would have been no model village there, since the local government could hardly leave $93.6 \%$ of the villagers without adequate help, and no means in sight to finance it for them.

Fourthly, model villages are government projects in nature, and their competition is also intense. The establishment of model villages involves social network relations, which is related to social capital (Lin, 2002; Cleaver, 2005). Communities with good social relations and good economic foundation and whose project can achieve remarkable results have higher competitive advantages. This is a short-term 
management approach centered on interests $(\mathrm{Li}, 2018)$, but it is of great significance to re-examine and re-understand the model village practice and governance reality in rural China (Ahlers and Schubert, 2013).

\section{ACKNOWLEDGE}

Li Yongxiang is a Distinguished Professor at National Center for Borderlands Ethnic Studies in Southwest China at Yunnan University, and Research Fellow at Yunnan Academy of Social Sciences.

\section{CONCLUSION}

This paper has discussed the political and economic significance of the model village, and the difference between the model and non-model villages after a landslide disaster. We need specific ways to evaluate model villages for looking at whether they are sustainable or not. Model village is related to the Chinese political system where low-level government jobs are mainly evaluated by high-level leaders, and the promotion of cadres is also decided by the high-level leaders. One reason for local governments' creating model villages is that they can easily show their success to high-level officers. Besides the possible promotion of local cadres, there are also economic reasons why the local government and villagers hope to get model village projects. That is, model villages can get more funds for infrastructure construction and improvement of living conditions. With the progress of targeted poverty alleviation strategy in rural China, model villages will be expanded in types and regions, and of course, it will attract academic attention. The construction of model villages in post-disaster recovery and reconstruction links the model villages with post-disaster reconstruction, and provides an idea for future post-disaster reconstruction. 


\section{REFERENCE}

Ahlers,Anna L.and Gunter Schubert.2013."Strategic Modelling:'Building a New Socialist Countryside' in Three Chinese Counties." The China Quarterly.Vol. 216, No. pp. 831-849.

Cleaver, Frances.2005. "The Inequality of Social Capital and the Reproduction of Chronic Poverty," World Development.Vol.33, No. 6, pp. 893-906.

Diamond, Norma.1983."Model Village and Village Realities.” Modern China,Vol.9, No.2, pp. 163-181.

Hong, Huan and Zheng shaoxiong.2012."Discussion on Promoting the Construction of Ecological Model Village of Green Development in Guangdong, China." Journal of Southwest Agricultural University(Social Sciences Edition).Vol. 10, No. 7, pp. 19-20.

Hu, Zhongping, Feng Yuan, Hu Ping, Xie Jianqing. 2011. "Analysis of Differences between New Rural Model Villages and Non-Model Villages Construction -- Based on the Survey of 38 Villages in Hu'nan province." Journal of Hunan Agricultural University(Social Sciences). Vol. 12, No. 6, pp. 39-44.

Huo Yongjun, Zhao Wu, Zhou Bo. 2017.“Analysis on the Construction Mode of Ecological Garden Model Village." Journal of Jishou University (Social Sciences).Vol. 38, No. s2, pp. 12-14.

Jia, Dongshui. 2017."Exploration and Practice of Targeted Poverty Alleviation Construction of Tourism Poverty Alleviation Model Village." Journal of Hebei University of Engineering(Social Science Edition).Vol. 34, No. 4, pp. 5-7.

Lan, Liangping. 2016. "Study on the Construction of Yunnan Ethnic Unity Model Village - A Case from Zheng Jiazhuang of Eryuan County." Journal of Guangxi Normal University for Nationalities. Vol. 33, No. 1, pp. 50-52. DOI: 10.19488/j.cnki.45-1378/g4.2016.01.014.

Li, Zupei. 2018. "Neo-agents': A Study of Village Governance under the 'Projects to Village Model." Chinese Journal of Sociology.Vol. 4, No.3, pp. 392-421.

Lin, Nan. 2002. Social Capital: A Theory of Social Structure and Action.Cambridge:Cambridge University Press.

Nakagawa, Yuko and Rajib Shaw. 2004. "Social Capital:The Missing Link to Disaster Recovery." International Journal of Mass Emergencies and Disasters. Vol. 22, No. 1, pp. 5-34.

Oliver-Smith, Anthony.1999. "“What is a Disaster?':Anthropological Perspectives on a Persistent Question.'In The Angry Earth: Disaster in Anthropological Perspective,edited by Anthony Oliver-Smith and Susanna M. Hoffman (eds.),.pp. 18 34. London: Routledge.

Oliver-Smith, Anthony. 2005. "Communities after Catastrophe: Reconstructing the Material, Reconstituting the Social." In Community Building in the Twenty-First Century, edited by Stanley E. Hyland (ed.),.pp. 45 70. Santa Fe, New Mexico: School of American Research Press, pp. 45-70.

Torry, William I. 1979. “Anthropology and Disaster Research.”Disasters.Vol. 3, No. 1, pp. 43-52.

Whiting, Susan H. 2001. Power and the Wealth in the Chinese Township: The Political Economy of Institutional Change in Rural Industry.New York: Cambridge University Press.

Yang, Wenlei, and Liu Hefang. 2018. "Thoughts on Project Construction of National Unity Model Village: A Case from Yongle Village of Hehua Township of Tengchong, Yunnan." Journal of Baoshan University.Vol. 27, No. 3, pp. 14-17.

Zhang, Qunhui. 2018. "Research on Sharing Development Concept and National Unity Model Village Construction." Journal of Honghe University.Vol.16, No. 3, pp. 5-8. 